\title{
Smart Agriculture System based on IoT and its Social Impact
}

\author{
Gokul L. Patil \\ Professor \\ Dept of Computer Engineering \\ Sandip Institute of Technology and \\ Research Centre, University of \\ Pune, Nashik, Maharashtra
}

\author{
Prashant S. Gawande \\ Dept of IT \\ Sandip Polytechnic \\ Nashik, Maharashtra
}

\author{
R. V. Bag \\ Professor \\ Dept of Computer Engineering \\ Matoshri College of Engineering and \\ Research Center
}

\begin{abstract}
Agribusiness required the devotion of numerous regular asset including, land, water, and ecological condition, The quality and amount of characteristic asset has debased throughout the years because of monetary issues related with expanded cost of info and diminishing ranch salary always declining land, labor, resources, and environmental issue, for example, soil and water contamination putting the suitability without bounds horticulture operation at chance. The solution for this, is to embrace the savvy agribusiness framework in light of IOT with help farming administration and development of products including less utilization of water, compost and pesticide.
\end{abstract}

\section{Keywords}

Smart Agriculture, Fertilizers, Sensors, Water Monitoring, Ph Level Monitoring, Development Board, IoT platform, MS (Moisture Sensor), TS (Temperature Sensor), PS (Pressure Sensor), HS (Humidity Sensor)

\section{INTRODUCTION}

Agriculture is the main backbone of Indian economical growth. The most important barrier that arises in traditional farming is climate change. The number of effects of climate change includes heavy rainfall most intense storm and heat waves, less rainfall etc. due to these the productivity decrease to the major extent. Climate change also raises the environmental consequences such as the seasonal change in the life cycle of the plant. To boost the productivity and minimize the barrier in agriculture field there is need to use innovative technology and technique called Internet of things. The technological advances in their areas gather increasing momentum and this means that maintaining as the overview. The most important things of smart farming are environmental measurement and water management. The reason is that the environmental and water management affect plant growth [6].

The paper aims at making agriculture smart using automation and IOT technologies. The highlighting features of this paper include smart irrigation with smart control based on real time field data. Secondly temperature maintenance, humidity maintenance and other environmental parameters. And finally the recommendation to farmer for smart agriculture.

\section{BENEFIT OF SMART AGRICULTURE}

Smart agriculture with the help of automation and sensor technology, benefits the society in the following ways [3]

- Conservation of water

- Optimization of energy resources.

- Better crop yield
- Pollution prevention

- Eliminate human errors

- Time efficiency, accurate diagnosis of nutrient deficiency

- Automation with low power consumption components

On the whole smart farming refers to data gathering, data processing, analyzing and automatic control system. Overview of smart agriculture system [6] as shown in figure

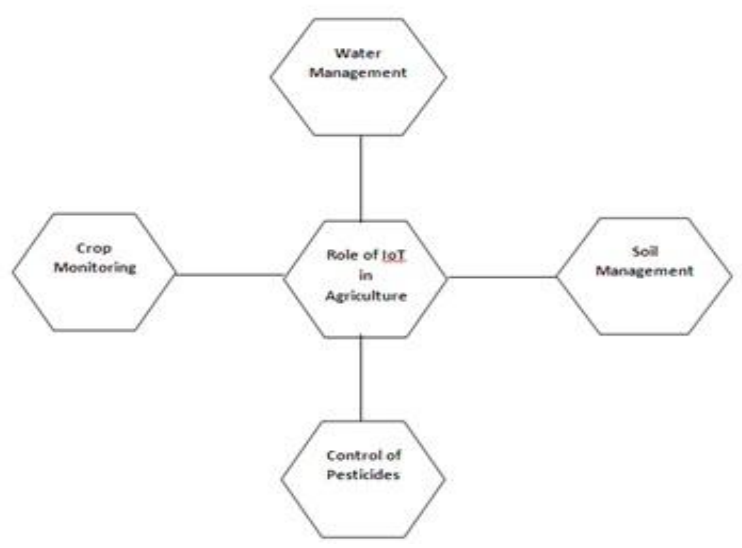

Figure 0. Overview of Smart Agriculture system

\section{LITERATURE SURVEY}

The scenario of decreasing water tables, drying up of rivers and tanks, unpredictable environment present an urgent need of proper utilization of water. To cope up with this use of temperature and moisture sensors at suitable locations for monitoring of crops is implemented in [8].An algorithm developed with threshold values of temperature and soil moisture can be programmed into micro controller based gateway to control water quantity. The system can be powered by Photo voltaic panels and can have duplex communication link based on cellular - Internet interface that allow data inspection and irrigation scheduling to be programmed through web page.[9].The technological development in open source software and hardware make it easy to develop the device which can make better monitoring and wireless sensor network made it possible to use in monitoring and control of green house parameter in precision agriculture.[7].

\section{PROPOSED SYSTEM OVERVIEW}

In the proposed system collecting all the data from various sensor like temperature, humidity, lux, moisture and other environmental factors and will do the analysis on the same. During analysis if gets better result of the combination of the data gathered from the various sensor then those data to all 
the volunteer for further use. In this system planning to use the IOT platform like xively (formally called pachube) for the analysis. The system will contain many module at various geographical position and all these modules will send the data to this platform, , which will give some idea to focus on the environmental factor, which are good for the crop or farm

\section{TECHNOLOGY REQUIRED}

To make the system one micro-controller which will process the data coming from the various sensor? Off-course sensors are the heart of the system and in this system use LM35 temperature sensor because this sensor gives the output in degree Celsius and also easy to interface.

\section{A. Temperature Sensor}

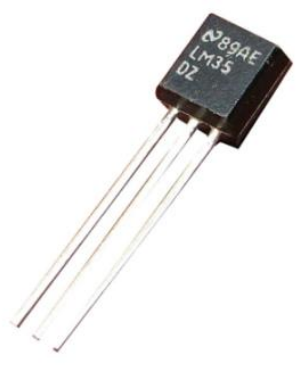

Figure.1 Temperature sensor LM35

Figure 1 Shows Photograph of a LM-35 Temperature Sensor. The change of soil temperature directly impact on soil nutrient absorption and soil moisture keep and sport. [5] The soil temperature plays a certain role on many of the physical processes of soil.

\section{B. Moisture Sensor}

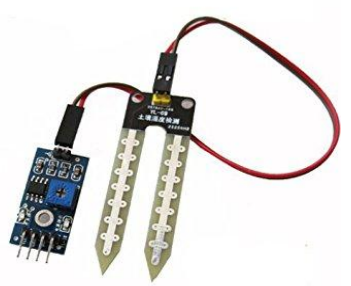

Figure 2. Moisture Sensor

Figure 2 sensors are used to sense the moisture content in the soil. It works on the principal of electrical conductivity. Resistance of the sensor is inversely proportional to moisture content in the soil.[1] Moisture content of the soil is a major factor determining plant growth. The present work Comprises of development of a soil moisture sensor. Figure 2 shows the Photograph of a Soil Moisture Sensor. Moisture sensor used as soil sensor [4].

\section{Pressure Sensor}

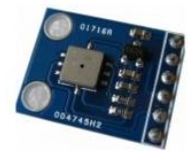

Figure 3. Barometric Pressure Sensor
It is known that heavy showers can be expected when the atmospheric pressure is low and rainfall is less likely to occur when pressure is high. Rainfall is inversely proportional to atmospheric pressure. The pressure sensors connected to the micro controller also regulate the water flow by stopping the supply when the pressure is lower than a threshold value. (The threshold value depends on the amount of rainfall received in the area of cultivation). The plants are watered using sprinklers or small nozzles. To avoid errors in pressure values due to external factors like animals or flapping of wings of birds, etc., the pressure value is determined by an average of pressure values taken from a number of sensors installed at different points in the field

\section{Humidity Sensor}

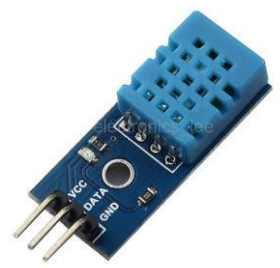

Figure 4.Humidity Sensor

Humidity sensors senses, measure the relative humidity in the air, it therefore measure moisture and air temperature humidity is the ratio of actual moisture in air to the highest amount moisture that can be held at that air temperature. Humidity Directly influences the water relations of plant and indirectly affect leaf growth, photo synthesis, pollination and finally economical yield. Leaf growth not only depends on synthetic activities resulting from biochemical process but also upon the physical process of cell enlargement.

\section{E. Microcontroller}

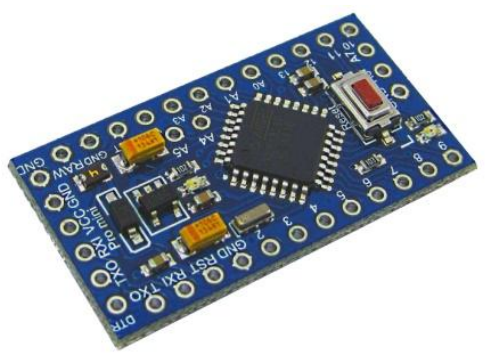

Figure 5. Arduino Mini Pro Board

In our system Arduino Pro Mini used because Arduino Pro Mini is a micro controller board based on the ATmega328.It has 14 digital input/output pins (of which 6 can be used as PWM outputs), 6 analog inputs, an on-board resonator, a reset button, and holes for mounting pin headers. A six pin header can be connected to an FTDI cable or Spark-fun breakout board to provide USB power and communication to the board. The Arduino Pro Mini is intended for semi-permanent installation in objects or exhibitions. The board comes without per-mounted headers, allowing the use of various types of connectors or direct soldering of wires. The pin layout is compatible with the Arduino Mini. There are two version of the Pro Mini. One runs at $3.3 \mathrm{~V}$ and $8 \mathrm{MHz}$, the other at $5 \mathrm{~V}$ and $16 \mathrm{MHz}$. The Arduino Pro Mini was designed and is manufactured by Spark-fun Electronics.[3] The strength of a plant is impacted by many factors, for example, stickiness, soil 
dampness content, supplement accessibility, measure of water/precipitation got, shade of the leaves, and so forth. The proposed framework goes for saving water and vitality by utilizing dribble water system technique and to screen the plants by keeping up the ideal temperature. Diverse sensors and actuators are being utilized to distinguish different parameters of the dirt like dampness, temperature, weight. At the point when any of the previously mentioned parameters cross a wellbeing edge which must be kept up to secure the plants, the sensors sense the change and the micro controller peruses this from the information at its information ports. On detecting the change, the micro controller at that point plays out the required activities by utilizing transfers until the strayed-out parameter has been taken back to its ideal level.

\section{AGRO LOGGER IN ACTION}

The system consists of 2 sections: agro logger and cloud interface with mobile application. In agro logger consists of integration of different sensors and devices and they are interconnected to one central platform (Xively) via wireless communication module

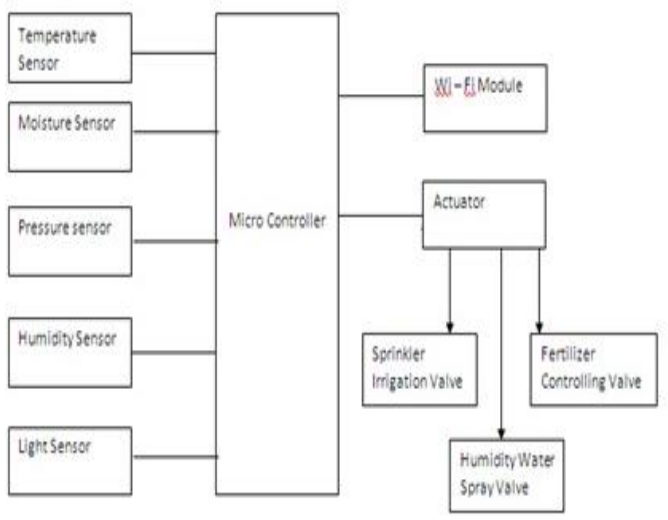

Figure 6. Architecture of Argo-Logger

The Xively send and receive information from user end using Internet connectivity. There are 2 modes of operation of system: auto mode and manual mode. In auto mode system takes its own decisions and controls the installed agro logger whereas in manual mode user can control the operations of system using android application.[2] An agro logger will provide smart agriculture features like temperature sensors, humidity sensors, moisture sensors, pressure sensors and light sensors and actuators consists of sprinkler irrigation valve, fertilizer controlling valve, humidity water spray valve

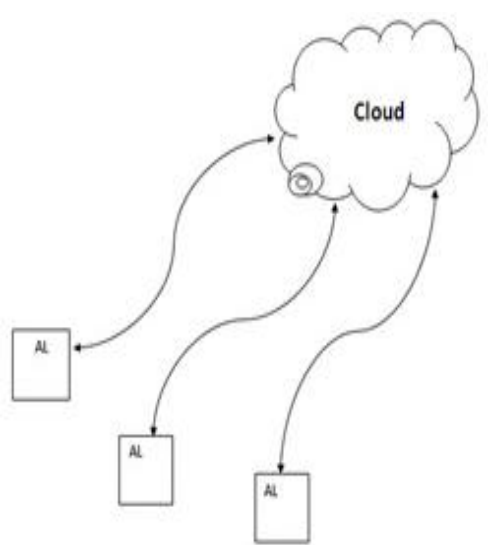

Figure 7.System Architecture
Temperature sensor and humidity sensor senses the temperature and humidity respectively and if the value crosses the threshold then room heater or cooling fan will be switched ON / OFF.
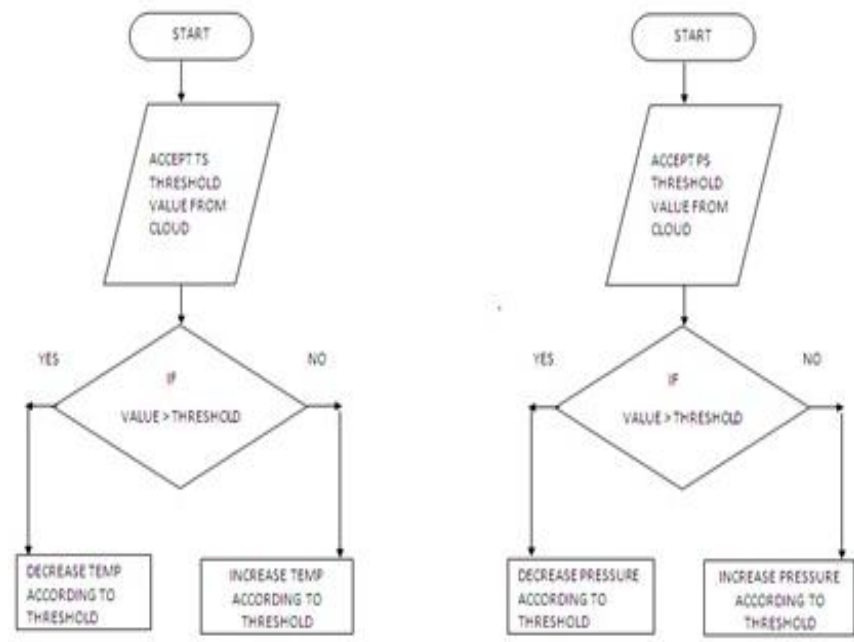

Figure 8. Flow chart of Sensors (Temperature \& Pressure)

Automatically providing temperature and humidity maintenance. In moisture sensors will control water pump depending upon soil moisture based on data provided by sensor time to time. i.e. automatically turning $\mathrm{ON} / \mathrm{OFF}$ the sprinkler irrigation valve after attaining the required soil moisture level in auto mode, switching sprinkler irrigation valve ON /OFF remotely via android app.
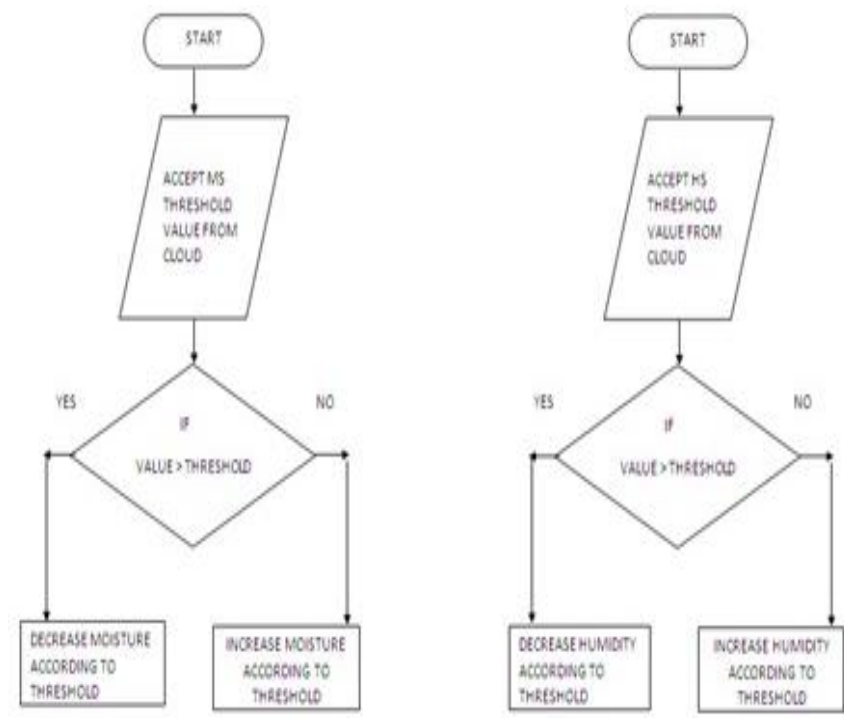

Figure 8. Flow chart of Sensors (Moisture \& Humidity)

In agro logger role of pressure sensor is that heavy showers can be expected when the atmospheric pressure is low and rainfall is less likely to occur when pressure is high. The pressure sensors connected to micro controller also regulate the water flow by stopping the supply when the pressure is lower than threshold value. 


\section{CONCLUSION}

This paper present Agro-logger system which is capable to send and receive the data from the sensors and also get the updated and precious data from the cloud. The cloud is connected to multiple Agro-logger and get updated by the large geographical area. This data is further analyze for the best selection criteria depends on the reviews given by the farmers and Agro-logger, then cloud will update the same data to the Agro-logger and vary the threshold value as per the selection criteria to improve crop productivity and soil fertility. In fig 6 describe the general architecture of Agrologger and fig 7 shows the actual system architecture for new system. For this system Arduino mini pro board select because the number of IO pins are sufficient to connect various sensors as describe in the paper, also the power consumption is very low even can run on mobile battery in case of power failure. Xively(formerly called pachube) is worldwide trusted platform for IOT right now, and connecting IOT devices is easy and can maintain the dataset from the same and gives the result in graphical format. Xively store, analyses the actionable result to improve performance and usability across devices and push updates based on live data.

\section{REFERENCES}

[1] Kaewmard,N., \& Saiyod,S. (2014). Sensor data collection and irrigation control on vegetable crop using smart phone and wireless sensor networks for smart farm. 2014 IEEE Conference on Wireless Sensors (ICWiSE). doi:10.1109/icwise.2014.7042670

[2] Nakutis, Deksnys,V., Jaruevicius,I., Marcinkevicius,E., Ronkainen,A., Soumi,P., ... Andersen,B. (2015). Remote Agriculture Automation Using Wireless Link and IoT Gateway Infrastructure. 2015 26th International Workshop on Database and Expert Systems Applications (DEXA). doi:10.1109/dexa.2015.37
[3] Srisruthi,S., Swarna,N., Ros,G.M., \& Elizabeth,E. (2016). Sustainable agriculture using eco-friendly and energy efficient sensor technology. 2016 IEEE International Conference on Recent Trends in Electronics, Information \& Communication Technology (RTEICT). doi:10.1109/rteict.2016.7808070

[4] Tan,L., Hou,H., \& Zhang,Q. (2016). An Extensible Software Platform for Cloud-Based Decision Support and Automation in Precision Agriculture. 2016 IEEE 17th International Conference on Information Reuse and Integration (IRI). doi:10.1109/iri.2016.35

[5] Umamaheswari,S., \& Preethi,A. (n.d.). Integrating Scheduled Hydroponic System. Paper presented at 2016 IEEE International Conference on Advances in Computer Applications (ICACA).

[6] Vinayak N. Malavade,Pooja K. Akulwar,Role of IoT in Agriculture, IOSR Journal of Computer Engineering (IOSR-JCE) e-ISSN: 2278-0661,p-ISSN: 2278-8727

[7] Nikesh Gondchawar, Prof. Dr. R.S. Kawitkar "IOT based Smart Agriculture," International Journal of Advanced Research in Computer and Communication Engineering(IJARCCE) June-16

[8] S.R. Nandurkar, V.R. Dhool "Design and Development of Precision Agriculture system using Wireless Sensor network" IEEE international Conference on Automation 2014

[9] Joaquin Gutierrez, Juan Francisco Villa-Medina "Automated Irrigation System using Wireless Sensor Network and GPRS module " IEEE Transaction,2013

[10] Arduino Pro Mini [online] https://www.arduino.cc/en/Main/ArduinoBoardProMini 